\title{
Convenience, savings, or lifestyle? Distinct motivations and travel patterns of one-way and two-way carsharing members in Vancouver, Canada
}

\author{
Rainer Lempert ${ }^{\mathrm{a}}$, Jiaying Zhao ${ }^{\mathrm{a}, \mathrm{b}}$, Hadi Dowlatabadi ${ }^{\mathrm{a}, *}$ \\ a Institute for Resources, Environment and Sustainability, The University of British Columbia, Canada \\ ${ }^{\mathrm{b}}$ Department of Psychology, The University of British Columbia, Canada
}

\begin{abstract}
A B S T R A C T
Carshare membership in North America has grown approximately 25\% per year over the past decade. Some have attributed this to pro-environmental values and low-impact lifestyles of millennials, the primary users of carsharing. Many municipal governments have adopted this belief and support carsharing through various accommodations and subsidies. Results from a survey in Vancouver, Canada (which has the highest level of carsharing in North America) showed that one-way and two-way carsharing members have different motivations for carsharing and travel patterns. One-way members, primarily millennials, self-report that they carshare for convenience, using shared vehicles twice as frequently and private vehicles three times as frequently as two-way members. Two-way members choose carsharing for financial savings and a more efficient lifestyle. They tend to walk and bike more often than one-way members and the overall Vancouver population. These trip mode and frequency differences are consistent across age, gender, income, and geography. Perhaps as a consequence of the above, we also found that while one-way members are on average younger and wealthier, two-way members self-report as having more affordable lifestyles. These findings point to two-way carsharing members adhering to more efficient, sustainable lifestyles. Municipalities may consider these differences in motivations and trip patterns between one-way and two-way members of relevance in their carsharing policies.
\end{abstract}

\section{Introduction}

Carsharing (also known as "car clubs" in the UK) is defined as "a membership program intended to offer an alternative to car ownership under which persons or entities that become members are permitted to use vehicles from a fleet on an hourly basis." (Murray et al., 2005). The first carsharing initiative was established in Switzerland in the late 1940s. However, it wasn't until the late 1980s that carsharing popularity grew in Europe. In the late 1990s and early 2000s carsharing began to spread to North America and Asia (Shaheen et al., 1999). Throughout the 2000s carsharing membership grew rapidly, aided by advances in Information Communication Technologies (ICTs). Smartphones lowered transactional costs associated with carsharing, making the service more convenient and affordable (Namazu, 2017).

Carsharing was, for five decades, restricted to a "two-way" (a.k.a. round-trip) system where members pick up the car at a specific location and later return it to that starting location. Globally, two-way carsharing has over 10 million members. In the late 2000 , advances in ICTs led to a new model of carsharing, "one-way" (a.k.a. free-floating) where users can pick up and drop off vehicles anywhere within a service area. Over the short span of a decade one-way carsharing has garnered nearly 5 million members and is growing rapidly. Today Car2go is the most popular one-way carsharing service with over 2.5 million members globally, while Zipcar is the most popular two-way service with 750,000 members. Since 2007, carsharing in North America has grown at a rate of $23 \%$ per year, from over to 200,000 members to nearly 2 million members (Shaheen, 2017).

\footnotetext{
* Corresponding author.

E-mail address: hadi.d@ubc.ca (H. Dowlatabadi).
} 
Car ownership now poses a long list of challenges to municipalities (e.g., congestion, air pollution, greenhouse gas (GHG) emissions, urban sprawl and suppression of other modes of transport). In response, governments have been keen to support transport alternatives that can lead to lower vehicle ownership, greater use of public transit, biking and walking. Carsharing is viewed as a viable alternative as it reduces car ownership, private vehicle usage and GHG emissions. An analysis by Martin et al. (2010) determined that the average carsharing vehicle removes between nine and 13 privately held vehicles from the road. Martin and Shaheen (2011) found that households participating in carsharing can be expected to reduce their carbon footprint by $0.84 \mathrm{t}$ GHG/year and their vehicle kilometers traveled (VKT) by 27\%. Namazu and Dowlatabadi (2015) estimated that households participating in two-way carsharing could reduce their annual GHG emissions by up to $54 \%$, determining that carsharing can positively impact environmental outcomes due to five factors: transportation mode change, fleet vintage, vehicle optimization, more efficient drive trains per vehicle type, and trip aggregation.

One-way and two-way carsharing differ in operational constraints, member profiles and outcomes with respect to car ownership, VKT and GHG emissions. Municipal governments should understand these differences in order to leverage these features through policy initiatives towards achieving their transportation goals. For example, Namazu and Dowlatabadi (2018) show that households that primarily use two-way carsharing had fewer cars before they joined the program ( 0.7 cars/household) but reduced car ownership by a further $50 \%$ - i.e. most gave up their only vehicle. However, one-way members started with 1.1 cars/household and after joining the carsharing program reduced their average car ownership by a mere $10 \%$. Thus, promotion of one-way and two-way carsharing would be targeting different types of households and achieving different levels of car ownership reduction. In addition to this, the barrier to entry for two-way membership is usually much higher (e.g., a large one-time deposit to join the program). Clearly, one-way and two-way members belong to different types of households even before joining carsharing services.

However, carsharing is often treated as a monolith by municipalities, where policies for one-way and two-way carsharing are often undifferentiated. For example, in Vancouver both one-way and two-way carsharing organizations pay the same subsidized yearly fee to obtain on-street vehicle parking permits (City of Vancouver, 2017). New York City's Carshare Pilot Program, which applies to both one-way and two-way services, aims to use carsharing to increase mobility options for lower income neighborhoods (NYC DOT, 2017). However, this is operationally more difficult to achieve with one-way carsharing than two-way, since one-way vehicles do not need to park at designated locations.

Conceptually, it is clear why municipal governments may wish to promote carsharing. In principle, carsharing offers reduced car ownership, reduced congestion, reduced GHG emissions, and the potential to increase transportation equity. We also know operational constraints that determine where one-way and two-way carsharing services can be offered. However, what is less well understood is what has been driving the growth in carsharing membership and whether there are differences across one-way and twoway carsharing members.

With the exception of Wielinski et al. (2015), Schaefers (2013) and Kashani and Trépanier (2018) much of the literature on carsharing has focused on service side logistics and optimization rather than user demographics and mobility needs. Our paper builds on their foundation and differentiates characteristics of one-way and two-way carsharing households and their trip frequencies and transportation mode choices.

To our knowledge, there are no studies detailing demographic characteristics of one-way and two-way carshare demand. However, previous studies have examined effects of the introduction of ridehailing on other modes of transportation, with different analyses reaching different conclusions. Hall et al. (2018) found that the introduction of Uber to metropolitan areas leads to an increase of public transit, with increasing effects over time. Sadowsky and Nelson (2017) found that after an initial spike, the introduction of ridehailing to a city leads to decreased transit use, a function of the convenience and cost-effectiveness of ride-hailing. Clewlow and Mishra (2017) survereyed users, asking ridehailing members if their travel patterns changed after joining Uber or Lyft. Among respondents who reported change in travel patterns, use of buses, light rail, and bicyle decreased while use of heavy rail and walking increased. We hope that our paper may provide some insight into the discrepencies between the results of these studies.

This paper was also informed by the rich literature of studies on demand for private car ownership. Dargay (2000) studied the influence of changing incomes on car ownership. He found that there is elasticity with respect to rising income but "stickiness" in response to falling income. Rising income levels allow people to own more cars but falling income levels are less likely to precipitate car shedding, as people become accustomed to their lifestyle and see their cars as necessities. Clark et al. (2016) developed a conceptual framework to determine changes in car ownership. They found that car ownership levels should not be considered as discrete decisions but as the culmination of life processes, influenced by various external stimuli and life events. Nolan (2010) also found that lifecycle events and household composition (such as number of children) are a significant determinant for car ownership. Oakil et al. (2016) determined that increasing urbanization and postponement of parenthood among young adults could reduce future car ownership. Shen et al. (2016) studied factors determining transportation mode choice in a large Chinese city. They found that income, job status, transportation subsidy, motivations related to comfort and safety, and shorter commuting distance all positively correlated with car ownership and use, while population density and proximity to metro stations has a negligible association with carshare use.

With these considerations in mind, this paper explores differences in travel patterns and motivations for carsharing between oneway and two-way carshare members across multiple demographic dimensions. Toward this goal, there are three objectives:

- Characterize the demographics of one-way and two-way carsharing members;

- Characterize stated motivations for carsharing and modal transportation patterns within one-way and two-way membership groups;

- Determine the relationship between income and affordability and carsharing membership. 
This paper is comprised of five sections. Section two describes the survey context, data, and methods. Section three uses multiple linear regressions and comparison of means across multiple demographics to describe differences in one-way and two-way user populations. Section four examines incongruities between income levels and perceived adequacy of incomes to sustain the lifestyles of one-way and two-way members. Section five is a discussion and summary of findings, their implications, and recommendations for policy and future research. The findings in the study pertain most directly to the city of Vancouver but are also generalizable to a North American context.

\section{Data}

\subsection{Target area: Metro Vancouver}

The study area is the Vancouver Metropolitan region of British Columbia, Canada - population 2.5 million. The city of Vancouver is the most populous and dense municipality of the Metro Region with a population approaching 650,000. Vancouver has more carsharing vehicles per capita than any other in North America, with 47.5 vehicles per 10,000 people (Vancity, 2018). In comparison, as of 2016 Vancouver has approximate 5500 private vehicles per 10,000 people (Metro Vancouver, 2016). The percentage of Vancouver residents over 18 with at least one carshare membership has grown steadily, from $13 \%$ in 2013 to $20 \%$ in 2014 to $26 \%$ in 2015 to $29 \%$ in 2016, the last year data was available (McElhanney, 2017).

However, carsharing is not evenly distributed across the entire population. People in different income brackets spend substantially different amounts on transportation. In 2016, the lowest income quintile of the British Columbia population spent, on average, $\$ 3753$ on private transportation while the highest quintile spent $\$ 18,375$ (Statistics Canada, 2011). These figures include private vehicle purchases, insurance, maintenance, gasoline, and other miscellaneous fees associated with private car ownership.

As of 2017, the time of the survey on which this study is based, Metro Vancouver was served by 4 different car share operators providing two-way (Modo and Zipcar) and one-way (Car2go and Evo) carsharing options to their members.

\subsection{The survey}

We conducted a survey focused on characterizing carshare usage and member motivations. The survey was distributed via an online platform to carsharing members in Metro Vancouver. Participants were recruited by their carsharing provider via monthly newsletter, in-app notification, and social media. A prize draw for carshare credits was given as an incentive by each provider. Survey responses were collected between October 5 and 22, 2017.

In total, 4010 participants completed the survey ( $54 \%$ females, mean age $=35.3$ years). Three quarters of respondents reside in the city of Vancouver, while the rest are spread across neighboring municipalities. Of our respondents, 2996 belonged only to oneway carsharing, either Evo, Car2go, or both. 248 of the respondents belonged only to two-way carsharing, either Modo, Zipcar, or both. The remaining 766 respondents belonged to both one-way and two-way carsharing. This group were left out of the analysis because our data precluded differentiation of user motivations by service type.

These respondents are taken to be from a population of $\sim 200,000$ one-way carsharing members and $\sim 20,000$ members of 2-way carsharing (Modo has 18,000 members, but Zipcar membership data is not public). Our sample of one-way members may not be fully representative because of usage heterogeneity, which is a limitation with our analysis. We are confident in our sample of two-way members being representative (pers. comm. Modo).

Survey questions include information on population demographics, trip patterns by modes of travel, number of cars owned per household, one-way vs two-way membership, income, "subjective affordability index", Likert-scale ranked attitudes towards car ownership and ride-sharing, and Likert-scale ranked motivations for carshare usage. Questions were strategically ordered to limit response bias due to order effects.

We received information on members geographic location but it was not factored into the analysis. At the time of the survey, approximately $95 \%$ of vehicles and utilization for one-way carsharing was located within the city of Vancouver. Two-way carsharing stations and membership extend to other municipalities, with approximately $1 / 3$ of our responses coming from Victoria. However, travel patterns and motivations for two-way carshare members are not significantly different in Victoria and Vancouver (see Table 6, Supplemental Information, for a description of two-way travel differences between Victoria and Vancouver residents).

In order to provide context for how one-way and two-way carshare users in Metro Vancouver compare to the broader population, demographic results of the survey have been compared to results from the 2016 Vancouver Metropolitan Area census (Fig. 1). Oneway and two-way users have similar gender breakdowns to each other and the overall population, with more females than males using both one-way and two-way services. The age breakdown of two-way members is also similar to the general population, skewing slightly younger but still maintaining a fairly even distribution of members across different decades. One-way users, however, skew much younger, with a plurality of surveyed users between 19 and 30 years old and only $10.6 \%$ of surveyed users 51 years or older. More than three quarters of one-way users are 40 years of age or younger, qualifying them as members of the millennial generation.

In the sections to follow, travel patterns and motivations will be analyzed for one-way and two-way users. While many of these analyses treat age as an explanatory variable, it is useful to remember the overall discrepancies in age and income (Fig. 2) between one-way and two-way carshare users. One-way users tend to be younger and wealthier than two-way users. While the distinctions between the one-way and two-way members remain constant over different demographic groups, it is useful to note other demographic distinctions between these two groups. One-way users, in our sample, represent a subset of wealthy millennials from the overall Metro Vancouver population, while two-way users are more demographically similar to the overall population. 

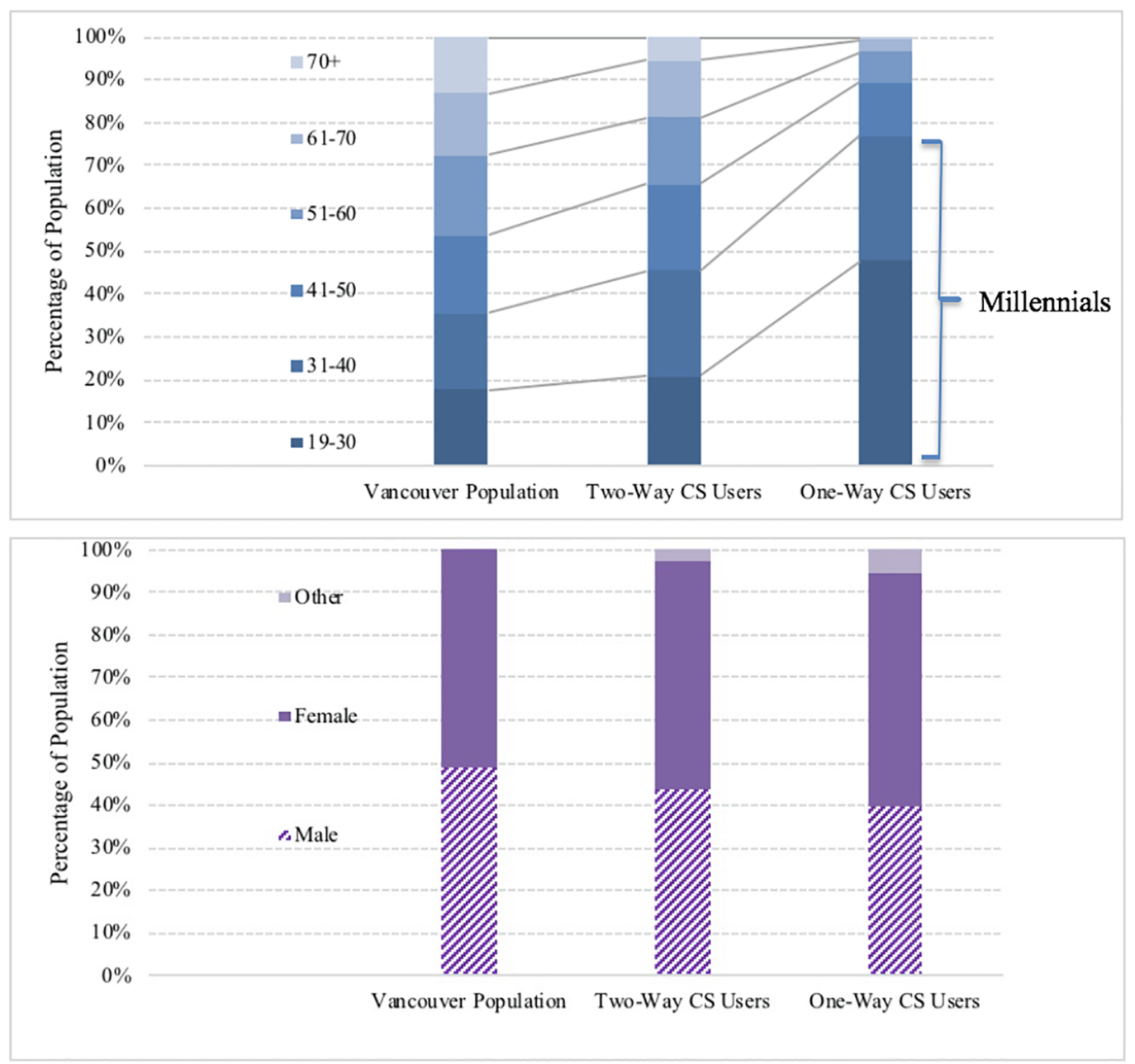

Fig. 1. Age and gender breakdown of Vancouver population (2016 Canada Census), one-way CS users, and two-way CS users.

\section{Results: motivations and travel modes among one-way and two-way users}

\subsection{Motivations for CS use}

Motivations for carsharing were assessed by four sections in the survey, each with multiple questions, probing various aspects and providing opportunities for gauging respondent consistency (reproduced in full in the SI). The first section asked about overall reasons for carsharing, the second contained questions about how carsharing fits into financial decision making, the third had questions related to how people used carsharing to travel, and the fourth asked about how carsharing impacts respondents' state of mind. Respondents could select "Agree (5)", "Mildly Agree (4)", "Neutral (3)", "Mildly Disagree (2)", or "Disagree (1)" for each of the statements they were invited to evaluate. Fig. 3 presents the mean ratings on each motivation for one-way and two-way carshare members. Because data were not normally distributed, unpaired two-sample Wilcoxon test was performed on each motivational question to compare the means of both samples.

As shown in Fig. 3, there were differences in motivations between one-way and two-way members for most categories. Two-way members were more motivated by financial and environmental reasons (i.e., saving money and reducing their carbon footprint) than one-way members. They overwhelmingly agreed that carsharing allows them to reduce their dependence on vehicle ownership and were more motivated to use carsharing as a means to achieve greater life efficiency. On the other hand, one-way members were more motivated by the added convenience and safety of carsharing and didn't necessarily see the service as a way to reduce their dependence on private vehicles. Instead, they viewed carsharing as a replacement for ridehailing services Uber or Lyft (which are absent in Vancouver), and are more likely to compare the cost of carsharing to using taxis. One-way members are far less likely to attribute carsharing as a means of traveling outside the city, implying that they use their personal vehicles for these longer trips.

It is possible that underlying variables helped determine these transportation pattern differences between one-way and two-way users. To check against this, a series of regressions was performed to assess the explanatory power of demographic features on modal 


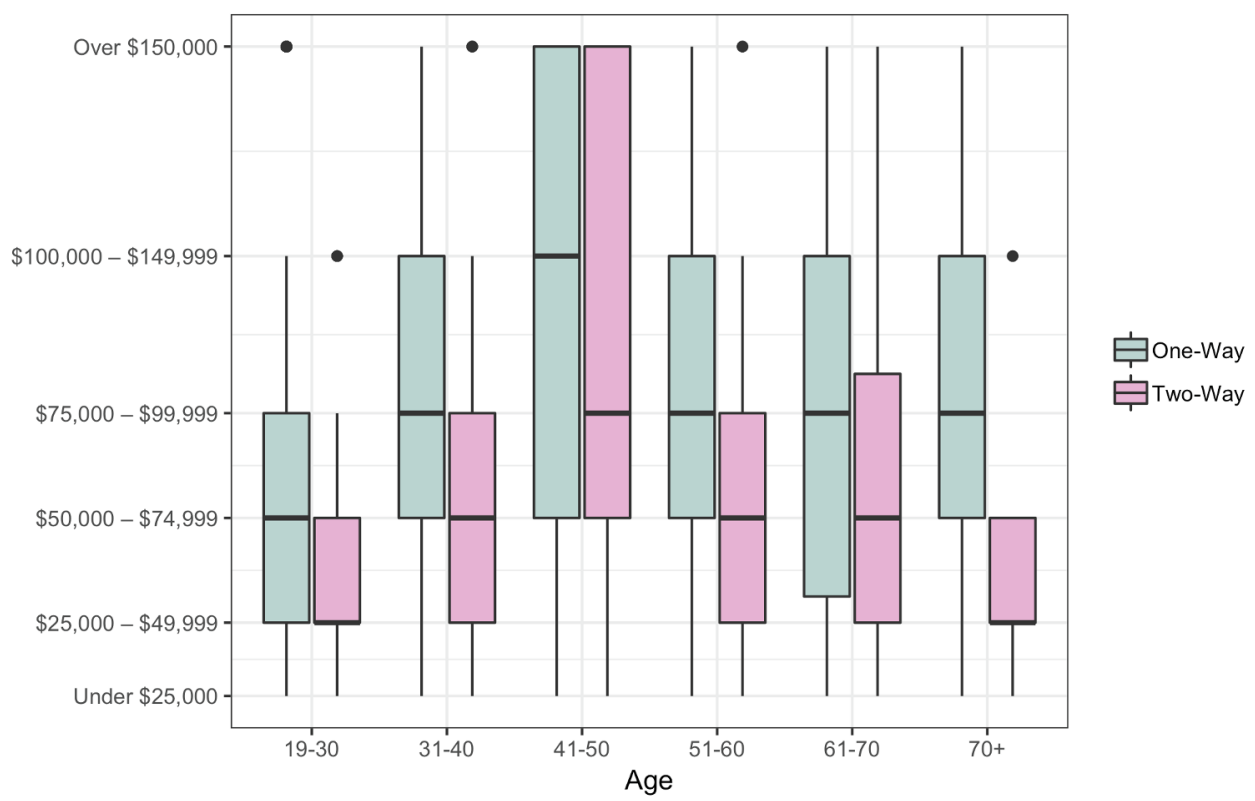

Fig. 2. Income of one-way and two-way CS users by age. One-way members are wealthier in all age brackets.

transportation usage. These regressions add to the statistical rigor of this analysis and complement the unpaired two-sample Wilcoxon tests. The regressions follow the formula:

$$
\text { motivation }_{i j}=\left\lceil\beta * \text { twoway }_{i}+\sum_{k}^{n} \gamma_{k} * d_{i k}\right\rceil j
$$

The dependent variable, motivation $_{i j}$ is individual $\mathrm{i}$ and carsharing motivation $\mathrm{j}$. The explanatory variables are twoway, a dummy variable equal to 1 if the user is a two-way member and 0 if the user is a one-way member and $d_{i k}$, demographic k for individual i. The demographics chosen include age, gender (represented as a dummy variable, with male $=0$ and female $=1$ ), number of drivers per household, number of road-worthy vehicles per household, number of children per household, affordability index (for more information see Section 4) and household income.

Only four of the regressions performed had multiple $\mathrm{R}^{2}$ values greater than 0.10 (Fig. 1). The question "do you carshare because of no access to Uber of Lyft?" had a multiple $\mathrm{R}^{2}$ value of 0.11 . "Do you compare the cost of carshare to vehicle ownership?" had a multiple $\mathrm{R}^{2}$ value of 0.17 . "Does carshare help you live efficiently" had a multiple $\mathrm{R}^{2}$ of 0.12 . Finally, "does carshare help you travel outside the city" had a multiple $\mathrm{R}^{2}$ of 0.15 . In all cases carshare choice was a significant indicator, with p-values below 0.01 . Carshare choice helped explain Likert scale score in the same direction as seen in the comparison of means analysis.

These four questions illustrate the differences between motivations for one-way and two-way carshare membership. One-way members see carsharing as a substitute for ridehailing services such as Uber or Lyft while two-way members view carsharing as a substitute for vehicle ownership. While both one-way and two-way members view carsharing as a means for convenience, only twoway members preferentially view it as a means for living more efficiently. Finally, two-way members view carsharing as a way to travel outside the city.

While these four models have the most notable multiple- $\mathrm{R}^{2}$ values, results of other regressions support the Wilcoxon test results. One-way or two-way carshare membership is a significant explanatory variable within most regressions, and the direction of explanation is similar to the difference of means tests.

To further check against underlying variables causing the discrepancies in motivational responses for one-way and two-way members, results were filtered by demographic levels for age, gender, income, and affordability index. Response patterns remain consistent across levels (Tables 7 and 8, SI). While other demographics do impact answers to the survey questions, as seen in Table 1, the one-way and two-way distinction largely transcends survey measured demographics. This suggests two distinct populations with separate lifestyles and motivations for using carsharing (see Table 2).

\subsection{Travel modes}

The previous section showed differences in one-way and two-way members motivations for carsharing. This section aims to see if these motivations are reflected in members transportation choices and patterns. Fig. 4 is a visualization of the average travel pattern for one-way and two-way carsharing members. The radial diagram displays the average number of trips per week for each mode of transportation (from 0 to 12). Because data were not normally distributed, an unpaired two-sample Wilcoxon test was performed on each travel mode to compare the means of both samples. Due to the eight travel modes not being independent, Bonferroni correction 


\section{Do you carshare because of:}

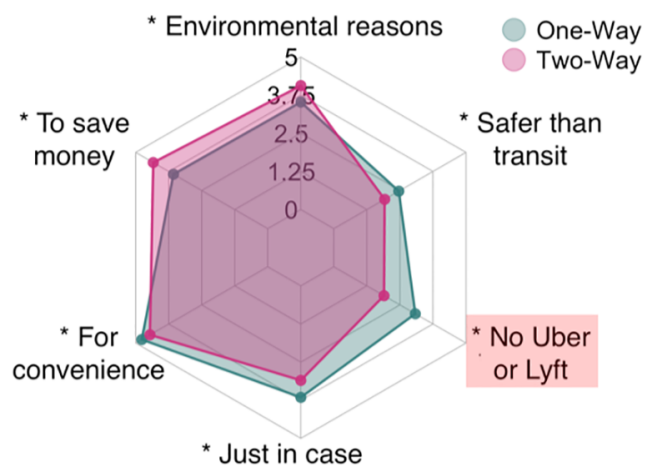

Do you compare the cost of carsharing to:

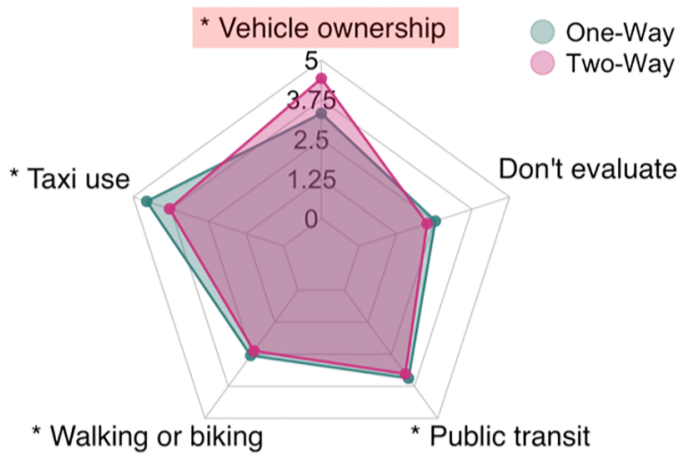

\section{Does carsharing help you:}

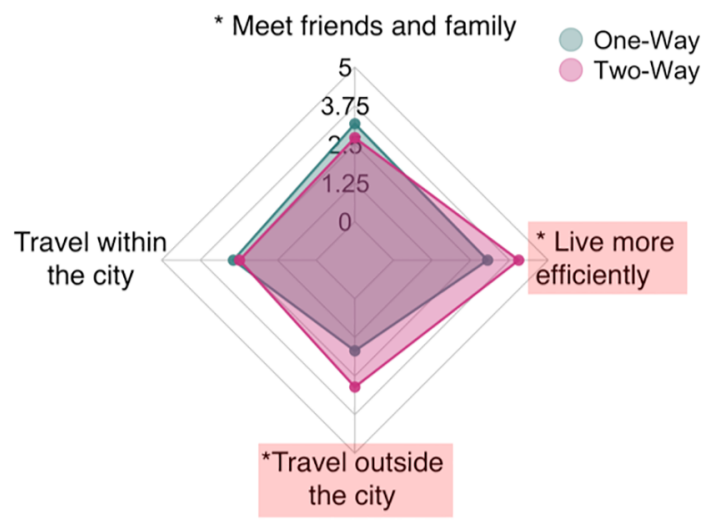

Does carsharing benefit your state of mind in these ways: Personal freedom

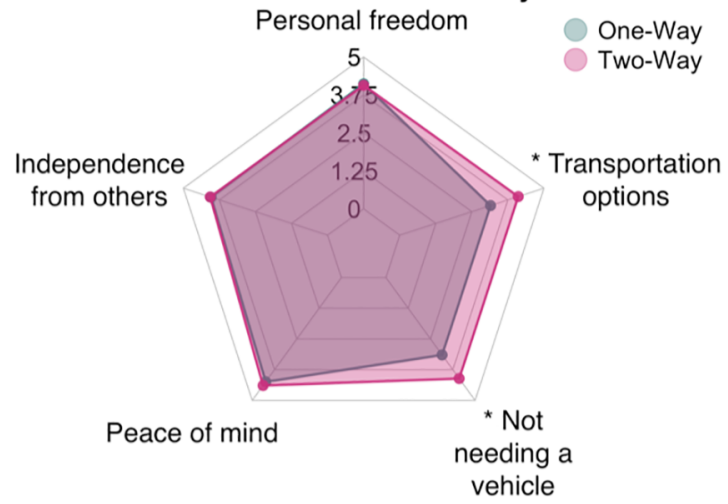

Fig. 3. Each spider diagram represents the mean response of one-way and two-way carsharing members to (a) overall motivations, (b) trip purpose, (c) economic reasoning, and (d) attitudinal motivations. In each, case, the axis marked with a * displays a difference between the two carsharing categories at the $95 \%$ significance level. Highlighted questions signify that the Likert scale scores were significantly explained by demographic variables, including carshare membership type, in a regression model.

was applied to counteract the problem of multiple comparisons. Mean differences in all modes with the exception of public transit and taxi service are considered significant with a p-value less than alpha/n $(0.05 / 8=0.00625)$.

Two-way users tend to walk and bike more frequently than one-way users. On average they walk 1.8 and bike 1.2 more times per week. One-way users travel by private cars more than three times as frequently as two-way users, and they carshare more than twice as frequently. One-way users also averaged 2.27 more total trips per week than two-way users. However, without closely examining household demographic characteristics it is difficult to draw meaningful conclusions from that particular comparison.

It is possible that underlying variables helped determine these transportation pattern differences between one-way and two-way users. To check against this, a series of regressions was performed to assess the explanatory power of demographic features on modal transportation usage. These regressions are similar to the ones performed in the previous section and follow the formula:

$$
\operatorname{mode}_{i j}=\left\lceil\beta \cdot \text { twoway }_{i}+\sum_{k}^{n} \gamma_{k} \cdot d_{i k}\right\rceil j
$$

The dependent variable, mode $_{i j}$ is individual $\mathrm{i}$ and mode use $\mathrm{j}$. The explanatory variables are twoway, a dummy variable equal to 1 if the user is a two-way member and 0 if the user is a one-way member, and $d_{i k}$, demographic $\mathrm{k}$ for individual $\mathrm{i}$. The demographics chosen include age, gender (represented as a dummy variable, with male $=0$ and female $=1$ ), number of drivers per household, number of road-worthy vehicles per household, number of children per household, affordability index (for more information see Section 4) and household income.

This model was run for all eight modes of transportation. The multiple $\mathrm{R}^{2}$ value was low, with a value less than 0.1, for travel modes other than driving a private vehicle (Table 1 ), which had a multiple $\mathrm{R}^{2}$ value of 0.25 . Due to the construction of the dummy variable for carshare membership, with 0 signifying a one-way membership and 1 signifying a two-way membership, this model shows that one-way membership significantly explains increasing numbers of trips per week in a private vehicle. Other regressions, while having less explanatory multiple- $\mathrm{R}^{2}$ values, had similar results to the Wilcoxon tests. Carshare membership choice significantly 
Table 1

Multivariable linear regression estimating predictive power of demographic variables on Likert scale responses to motivational questions. For "Carshare Type" dummy variable construction, one-way $=0$ and two-way $=1$. For "Gender" dummy variable construction, male $=0$ and female $=1 .{ }^{*}$ indicates p-value $<0.05, * *$ indicates p-value $<0.01$.

\begin{tabular}{|c|c|c|c|c|c|c|c|c|c|}
\hline \multirow[t]{2}{*}{ Carshare Motivation } & \multirow[t]{2}{*}{ Multiple-R ${ }^{2}$} & \multicolumn{2}{|c|}{ Carshare Type } & \multicolumn{2}{|l|}{ Age } & \multicolumn{2}{|l|}{ Income } & \multicolumn{2}{|l|}{ Gender } \\
\hline & & P-Value & Estimate & P-Value & Estimate & P-Value & Estimate & P-Value & Estimate \\
\hline Saves money relative to owning a vehicle & 0.17 & $<0.01^{* *}$ & 0.37 & 0.44 & 0.02 & $<0.01^{* *}$ & -0.07 & 0.55 & 0.01 \\
\hline Easier to go to more places outside the city? & 0.15 & $<0.01 * *$ & 0.85 & $<0.01 * *$ & -0.11 & $<0.01^{* *}$ & -0.16 & 0.19 & -0.02 \\
\hline Easier to live efficiently? & 0.12 & $0.02 *$ & 0.18 & $<0.01^{* *}$ & -0.06 & $<0.01^{* *}$ & -0.09 & 0.58 & 0.01 \\
\hline Replace Uber/Lyft Motivations & 0.11 & $<0.01 * *$ & -0.49 & $<0.01^{* *}$ & -0.26 & $<0.01^{* *}$ & 0.06 & 0.56 & -0.01 \\
\hline Easier to see friends/family? & 0.08 & $<0.01 * *$ & -0.25 & $<0.01 * *$ & -0.18 & 0.07 & -0.04 & $<0.01^{* *}$ & 0.06 \\
\hline Like not owning a vehicle & 0.07 & $<0.01^{* *}$ & 0.34 & 0.11 & 0.03 & 0.70 & -0.008 & 0.26 & 0.02 \\
\hline Easier to go to more places inside the city? & 0.06 & 0.91 & -0.009 & $<0.01 * *$ & -0.11 & $<0.01 * *$ & -0.15 & 0.32 & 0.02 \\
\hline Environmental Motivations & 0.05 & $<0.01 * *$ & 0.28 & $<0.01^{* *}$ & 0.13 & 0.36 & -0.02 & $<0.01 * *$ & 0.13 \\
\hline Compare cost to walking/biking & 0.04 & $0.04 *$ & -0.16 & $<0.01^{* *}$ & -0.10 & $0.02 *$ & -0.05 & 0.91 & -0.002 \\
\hline Enjoy the freedom & 0.04 & 0.93 & 0.007 & $<0.01^{* *}$ & -0.06 & $<0.01 * *$ & -0.09 & $<0.01^{* *}$ & 0.07 \\
\hline Knowing I have personal mobility when needed & 0.04 & $0.04 *$ & 0.16 & $0.04 *$ & -0.04 & $<0.01^{* *}$ & -0.10 & $<0.01^{* *}$ & 0.05 \\
\hline Financial Motivations & 0.03 & $<0.01 * *$ & 0.45 & $<0.01 * *$ & 0.07 & 0.89 & 0.003 & 0.06 & -0.04 \\
\hline "In case you need it" Motivations & 0.03 & $<0.01^{* *}$ & -0.26 & 0.34 & 0.02 & $<0.01^{* *}$ & -0.07 & 0.76 & -0.006 \\
\hline Safety Motivations & 0.03 & $<0.01^{* *}$ & -0.31 & $0.01 *$ & -0.06 & $<0.01 * *$ & -0.10 & $<0.01^{* *}$ & 0.06 \\
\hline Saves money relative to taxi & 0.03 & $<0.01^{* *}$ & -0.57 & 0.99 & -0.0003 & 0.31 & 0.02 & $0.03^{*}$ & 0.04 \\
\hline Convenience Motivations & 0.02 & $<0.01^{* *}$ & -0.47 & 0.18 & -0.03 & $0.01 *$ & 0.05 & $0.04 *$ & 0.03 \\
\hline Compare cost to public transit & 0.03 & $<0.01 * *$ & -0.35 & $<0.01 * *$ & -0.13 & 0.90 & -0.003 & 0.29 & 0.02 \\
\hline Do not evaluate cost & 0.02 & 0.30 & -0.08 & 0.17 & 0.03 & 0.53 & -0.01 & 0.05 & -0.04 \\
\hline Not having to rely on others for a ride & 0.03 & 0.95 & 0.004 & 0.06 & -0.04 & $<0.01 * *$ & -0.07 & $<0.01 * *$ & 0.06 \\
\hline Like having different options for getting around & 0.006 & 0.09 & -0.13 & 0.90 & -0.003 & 0.62 & 0.01 & $<0.01^{* *}$ & 0.06 \\
\hline
\end{tabular}

\section{Table 2}

Multivariable linear regression estimating predictive power of demographic variables on number of trips per week via private vehicle. For "Carshare Type" dummy variable construction, one-way $=0$ and two-way $=1$. For "Gender" dummy variable construction, male $=0$ and female $=1$. * indicates p-value $<0.05, * *$ indicates p-value $<0.01$.

\begin{tabular}{|c|c|c|c|c|c|c|c|c|c|}
\hline \multirow[t]{2}{*}{ Transportation Mode } & \multirow[t]{2}{*}{ Multiple - $\mathrm{R}^{2}$} & \multicolumn{2}{|c|}{ Carshare Type } & \multicolumn{2}{|l|}{ Age } & \multicolumn{2}{|l|}{ Income } & \multicolumn{2}{|l|}{ Gender } \\
\hline & & P-Value & Estimate & P-Value & Estimate & P-Value & Estimate & P-Value & Estimate \\
\hline Walking & 0.06 & $0.03 *$ & 0.16 & $0.02 *$ & -0.05 & 0.79 & 0.01 & 0.16 & -0.03 \\
\hline Biking & 0.03 & $<0.01^{* *}$ & 0.24 & 0.62 & 0.01 & 0.18 & 0.03 & $<0.01 * *$ & -0.07 \\
\hline Transit & 0.11 & 0.66 & -0.03 & $<0.01^{* *}$ & -0.16 & $<0.01^{* *}$ & -0.17 & 0.64 & -0.01 \\
\hline Carpool & 0.03 & 0.25 & 0.08 & $<0.01^{* *}$ & -0.11 & 0.57 & 0.01 & 0.14 & 0.03 \\
\hline Taxi & 0.02 & 0.11 & -0.13 & $<0.01^{* *}$ & -0.07 & $<0.01^{* *}$ & 0.12 & 0.91 & 0.002 \\
\hline Carshare & 0.06 & $<0.01 * *$ & -0.40 & $<0.01 * *$ & -0.13 & 0.19 & -0.03 & 0.35 & -0.02 \\
\hline Private Vehicle (Passenger) & 0.06 & $<0.01^{* *}$ & -0.26 & 0.15 & 0.03 & $0.01 *$ & 0.05 & $<0.01^{* *}$ & 0.11 \\
\hline Private Vehicle (Driver) & 0.25 & $<0.01^{* *}$ & -0.25 & $<0.01^{* *}$ & 0.06 & $<0.01^{* *}$ & 0.12 & $<0.01 * *$ & -0.05 \\
\hline
\end{tabular}

explains trip use for walking, biking, carsharing, and operating a private vehicle. Two-way members are more likely to walk and bike, while one-way members are more likely to drive.

To complement the regressions and test for the explanatory power of other demographics on trip patters, further analysis was performed across other demographic levels. Members were separated by their gender, income, self-reported affordability index, and age. Trip patterns were determined for levels within these demographics. While transportation mode use varies across demographics, the same general difference in travel patterns between one-way and two-way members is present at almost every level. Table 5 (SI) shows the difference in weekly trips per mode between one-way and two-way members across demographic levels. In particular, these results show that one-way members take significantly more trips in privately owned vehicles than two-way members, with consistently significant p-values across all demographics.

Differences in private vehicle trips per week can largely be explained by differences in vehicle ownership between one-way and two-way members. $70 \%$ of one-way members own at least one private vehicle, compared to only $30 \%$ of two-way members. However, even when comparing respondents who own at least one vehicle, one-way members still drive more frequently. One-way respondents who own a vehicle average 5.1 trips per week while two-way members who own a vehicle average 3.8 trips per week.

As a comparison to the overall population in Vancouver, Fig. 5 shows travel mode percentage for one-way and two-way members, relative to a longitudinal panel survey of 2000 residents from the City of Vancouver (City of Vancouver, 2016). The figure shows that both one-way and two-way carsharing members preferentially use more sustainable modes of transportation, including walking, biking, and public transit, relative to the overall city population. One-way members, however, have a travel pattern that is closer to panel survey population than two-way members. 


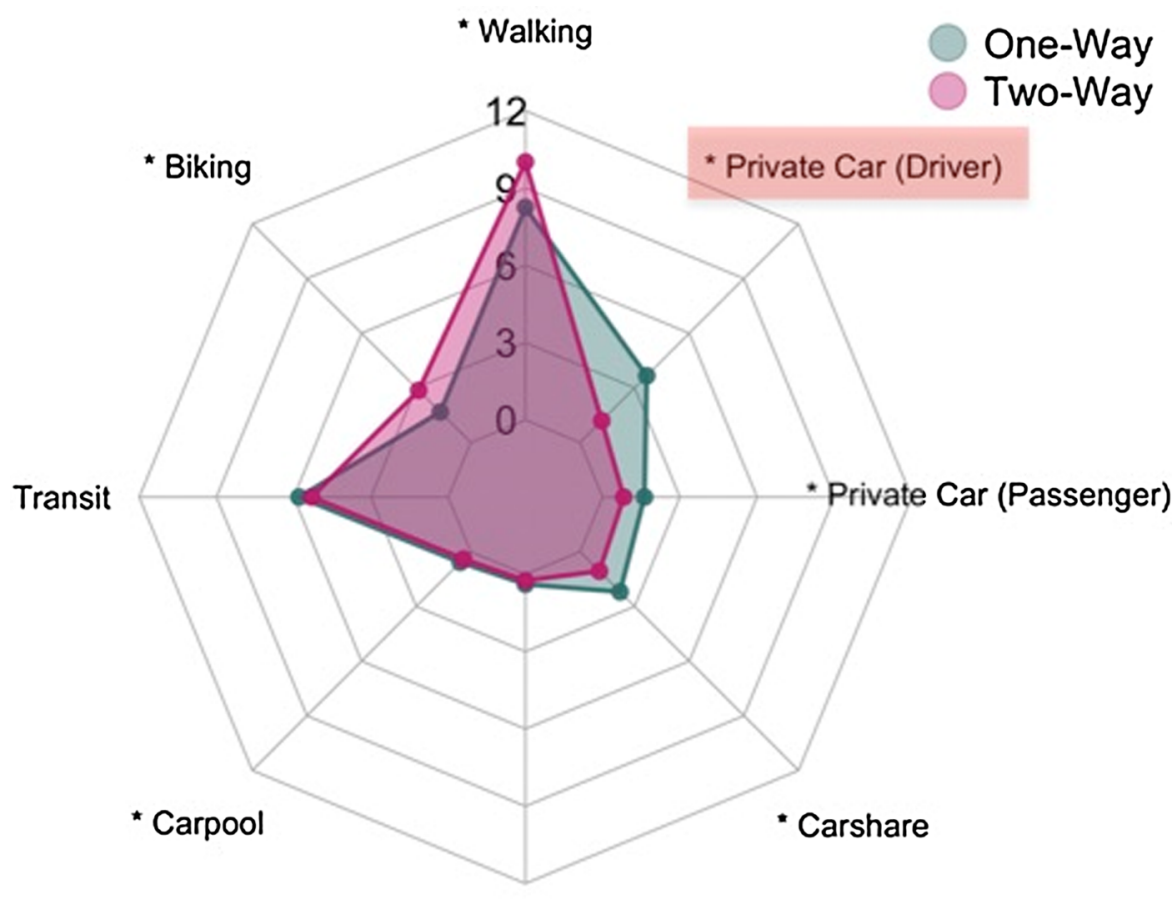

Taxi

Fig. 4. This spider diagram represents the weekly frequency of each mode of transportation as an axis with a scale from 0 to 12 . The average use of each mode by one-way and two-way carsharing members is plotted. Where the travel patterns differ at a statistically significant level, the label is marked. In each case, the axis marked with a * displays a difference between the two carsharing categories at the 95\% significance level. Private Car (Driver) is highlighted because it was significantly explained by demographic variables, including carshare membership type, in a regression model.

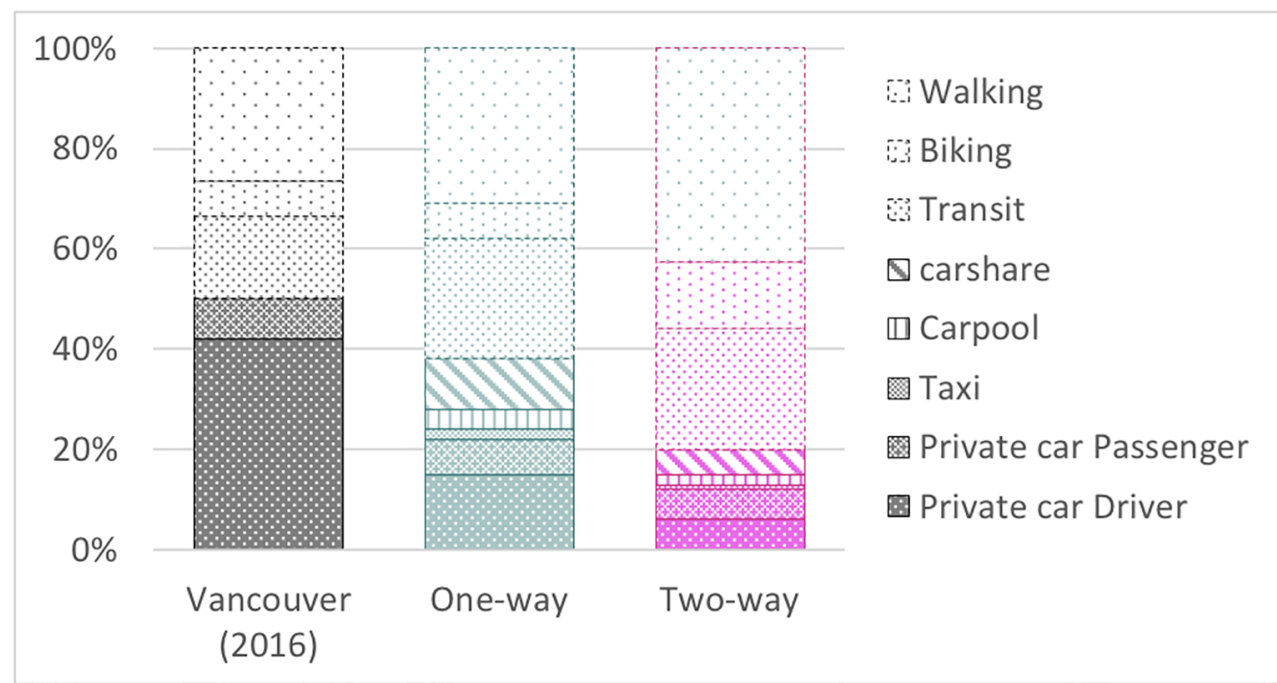

Fig. 5. A comparison of how modes of transportation vary across the overall Vancouverites and one-way and two-way carsharing members. Note that the Vancouver Panel Survey (McElhanney, 2017) did not measure taxi, carpool, and carshare trips. Boxes with heavy borders represent trips taken via an automobile, either private (passenger or driver), taxi, carpool, or carshare.

This analysis shows that there are clear distinctions in travel patterns between one-way and two-way carshare members. Differences exist between demographic levels, but within all levels two-way members preferentially use less expensive and more sustainable travel modes, making fewer trips by private vehicle and carshare. These travel patterns correspond to the motivations for one-way and two-way carshare use analyzed in the previous section. 


\section{Affordability vs. income for one-way and two-way CS users}

\subsection{Affordability index}

Studies of private demand for mobility often rely on income as a key independent variable. In this study, we are sensitive to the high cost of living in Vancouver possibly impacting income available for discretionary expenses and impacting demand for carsharing in lieu of car ownership. Therefore, income may not reflect the perceived affordability in our sample. To account for this discrepancy, we constructed the survey to gauge, in addition to income level, respondent's subjective perception of their lifestyle affordability.

Many household differences, such as the number of dependents, outstanding debts and patterns of discretionary spending can easily render a person with a higher income feeling their lifestyle to be less affordable. Those households which can modify their lifestyles to fit their incomes can be expected to find even the Vancouver region more affordable.

Before asking respondents to select their income bracket, we asked them "With respect to the cost of living in our region, would you say that: (a) I/my household find living here unaffordable or close to unaffordable; (b) I/my household meet our needs but cannot save for the future; (c) I/my household can comfortably meet our present and future needs; or (d) Prefer not to answer. For analysis in an ordinal logistic regression model, respondents who selected (a) were assigned a value of 0 , respondents who selected (b) were assigned a value of 1 , and respondents who selected (c) were assigned a value of 2 (respondents who answered (d) were filtered out of the analysis). These scores constitute what we refer to as an "affordability index." We note that the three levels are ordinal rather than interval or ratio. While it is a common practice in psychology to treat ordinal data on a gradient as interval ratio data (see de Winter and Dodou, 2010), we have used non-parametric analyses (e.g., ordinal logistic regressions) on the affordability index in Section 4.

To examine the relationship between affordability index and income, ordinal logistic regression was performed. The three levels of the affordability index were predicted by income. After scaling the incomes into standard deviations, the coefficient value was 0.56 with a standard error of 0.04 and a p-value of $<0.001$. This implies that as income increases by a full standard deviation the odds of observing a higher-ordered affordability response increase by $56 \%$. Although wealthier respondents tended to find Vancouver and its surrounding municipalities more affordable, there were some inconsistencies between the subjective construct of affordability and income levels. For example, approximately $15 \%$ of the respondents who found their lives to be "unaffordable or close to unaffordable" lived in households making over $\$ 100,000$, while approximately $10 \%$ of respondents who claimed to be able to meet their "present and future needs" lived in households with a combined income of less than $\$ 50,000$.

We believe the nexus of affordability and income may provide new insights for understanding carsharing motivations (e.g., whether people carshare out of necessity or convenience). In this section, we examine differences in income and affordability levels for one-way and two-way carshare members across different demographic groups. We hope to introduce further subtleties towards our understanding of one-way and two-way members and provide an example of the explanatory power of this new index.

\subsection{Discrepancies between affordability and income}

Because the affordability index and income level were measured by different scales (affordability was measured as an ordinal value, and income brackets ranged from less than $\$ 25,000$ to greater than $\$ 150,000$ ), in order to meaningfully compare the two parameters, the percent difference of each between one-way and two-users was calculated. For income, percent difference was calculated as the difference in the average income between one-way and two-way users (two-way minus one-way) divided by the mean income of both groups. Since affordability index is an ordinal value, a different approach was taken to calculate the percent difference. Respondents who selected either (b) and (c), living either fully or partly affordable lives, were combined into the "affordable group", while respondents who selected (a) were the "unaffordable group". The percentage of "affordable" participants in one-way and two-way members was computed and their difference was calculated (two-way minus one-way) as the percent difference. For both income and affordability, positive values indicate a higher score for two-way members compared to one-way members. As Fig. 6 shows, overall two-way members had 7.3\% lower income than one-way members, but there were $1.8 \%$ more twoway members in the affordable group.

Initially, we thought that age might explain differences in one-way and two-way affordability and income, given the differences in demographic makeup of the two populations (Fig. 1). However, this does not appear to be the case. One-way members are wealthier across all age levels. While two-way members do not report more affordable lives than one-way members across all ages, differences in affordability between two-way and one-way members are lower than differences in income for all age groups.

To further understand this discrepancy, we examined affordability, car ownership, and membership size within each income bracket (Table 3). Two-way members had a higher percentage of respondents in the "affordable group" than one-way members for all income brackets except \$100,000-\$149,999.

To gauge the significance of these relationships, we conducted another ordinal logistic regression. The three ordered levels of the affordability index were predicted by income and type of carsharing. As before, income had a coefficient value of 0.56 with a standard error of 0.04 and a p-value of $<0.001$. Type of carsharing was also significant, with a coefficient value of 0.09 (by dummy variable, one-way was coded as 0 and two-way as 1) with a standard error of 0.04 and a p-value of $<0.01$. This suggests that wealthier participants reported higher affordability than poorer participants, and two-way carsharing members reported higher affordability than one-way members

We also conducted a two-way ANOVA test to (income brackets: 6 levels $\times$ carsharing type: 2 levels one-way vs two-way) on the number of cars owned per household. We found that there was a main effect of income $[F(5)=39.68$, p $<.001]$, a main effect of 


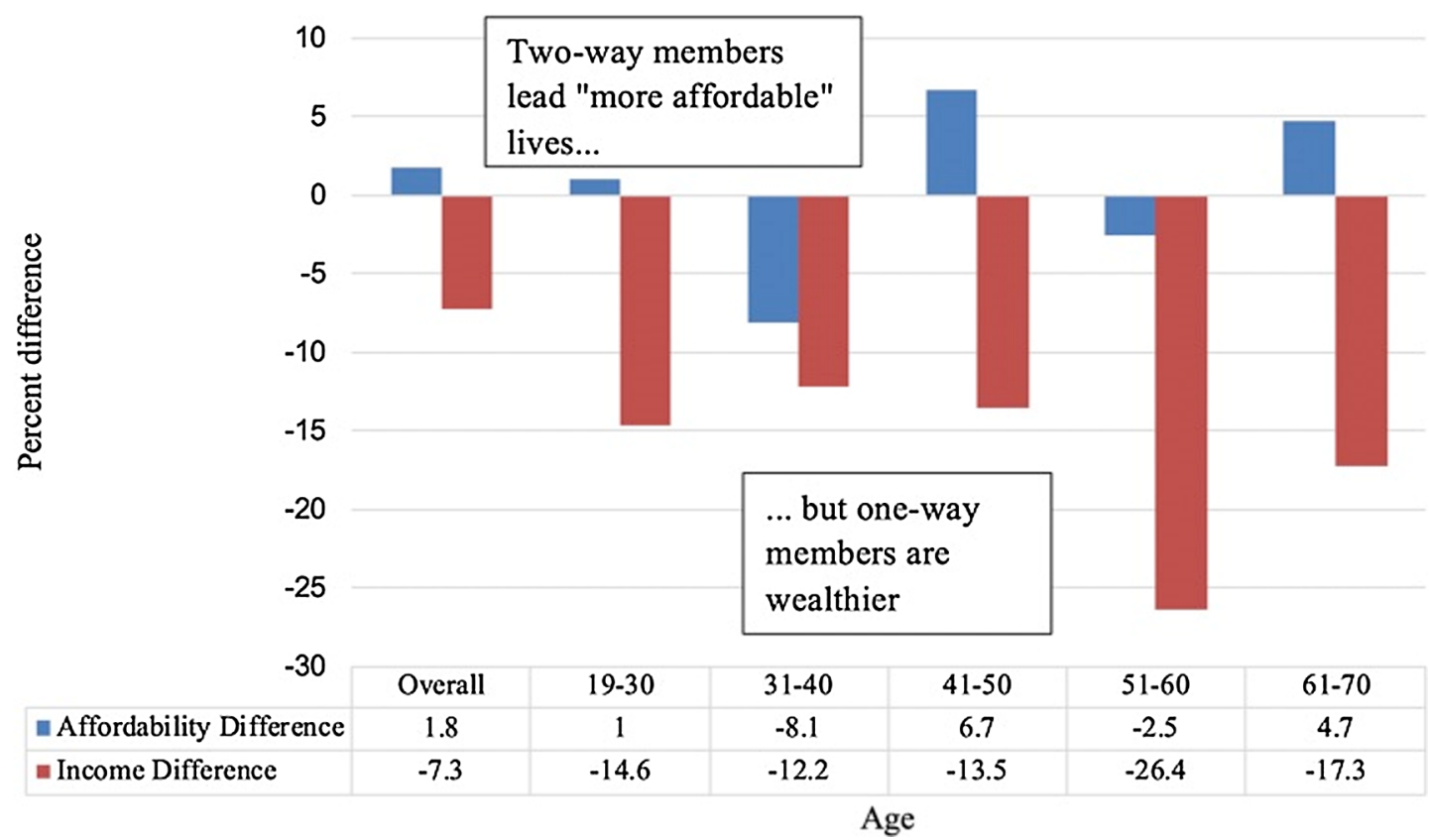

Fig. 6. Percent differences in the average affordability index (in blue) and average income (in red) between two-way and one-way carsharing members and broken down by age. Positive values reflect high affordability and income differences for two-way members. One-way members, on average, have higher incomes by $7.3 \%$, while two-way members report having a more affordable lifestyle by a margin of $1.8 \%$. (For interpretation of the references to colour in this figure legend, the reader is referred to the web version of this article.)

Table 3

Percentage in "affordable group" (selected b or c), mean cars per household, and sample size by income brackets.

\begin{tabular}{|c|c|c|c|c|c|c|}
\hline \multirow[t]{2}{*}{ Income bracket } & \multicolumn{2}{|c|}{ Percentage in "affordable group" } & \multicolumn{2}{|c|}{ Mean cars per household } & \multicolumn{2}{|l|}{$\mathrm{N}$} \\
\hline & One-way & Two-way & One-way & Two-way & One-way & Two-way \\
\hline$<\$ 25,000$ & $59 \%$ & $69 \%$ & 0.74 & 0.25 & 263 & 16 \\
\hline$\$ 25,000-\$ 49,999$ & $72 \%$ & $75 \%$ & 0.74 & 0.27 & 480 & 56 \\
\hline$\$ 50,000-\$ 74,999$ & $77 \%$ & $80 \%$ & 0.92 & 0.33 & 504 & 40 \\
\hline$\$ 75,000-\$ 99,999$ & $82 \%$ & $87 \%$ & 1.08 & 0.25 & 401 & 32 \\
\hline$\$ 100,000-\$ 149,999$ & $88 \%$ & $84 \%$ & 1.08 & 0.72 & 422 & 25 \\
\hline$>\$ 150,000$ & $90 \%$ & $95 \%$ & 1.51 & 0.8 & 283 & 20 \\
\hline
\end{tabular}

Table 4

Mean income, mean cars per household, and sample size by affordability index.

\begin{tabular}{|c|c|c|c|c|c|c|}
\hline \multirow[t]{2}{*}{ Affordability index } & \multicolumn{2}{|c|}{ Mean income } & \multicolumn{2}{|c|}{ Mean cars per household } & \multicolumn{2}{|l|}{ Percentage } \\
\hline & One-way & Two-way & One-way & Two-way & One-way $(\mathrm{N}=2353)$ & Two-way $(\mathrm{N}=189)$ \\
\hline $\begin{aligned} 0= & \mathrm{I} / \text { my household find living here unaffordable, or close to } \\
& \text { unaffordable }\end{aligned}$ & $\$ 62,644$ & $\$ 59,722$ & 1.00 & 0.33 & $20.5 \%$ & $18.7 \%$ \\
\hline $\begin{array}{l}1=\mathrm{I} / \text { my household meet our needs but cannot save for the } \\
\text { future }\end{array}$ & $\$ 74,047$ & $\$ 63,500$ & 0.95 & 0.41 & $52.7 \%$ & $46.0 \%$ \\
\hline $\begin{array}{l}2=\mathrm{I} / \text { my household can comfortably meet our present and } \\
\text { future needs }\end{array}$ & $\$ 114,023$ & $\$ 102,857$ & 1.16 & 0.4 & $26.7 \%$ & $35.2 \%$ \\
\hline
\end{tabular}

carsharing type $[\mathrm{F}(1)=73.35, \mathrm{p}<.001]$, but no interaction $[\mathrm{F}(5,1)=1.07, \mathrm{p}=.37]$. This suggests that wealthier participants owned more cars than poorer participants, one-way carsharing members owned more cars than two-way members, but the difference between one-way and two-way members remained the same across income brackets.

We note that the proportion of two-way members was higher in the $\$ 25,000-\$ 49,999$ bracket $(\mathrm{N}=56,30 \%)$ than in the other brackets. This suggests an income threshold to join two-way carsharing memberships (i.e., paying the $\$ 500$ membership fee), where below $\$ 25,000$ people may find the membership fee to be a barrier.

We also examined mean income, car ownership, and membership distribution within each affordability level (Table 4). 
As before, we conducted a two-way ANOVA (affordability index: 3 levels $\times$ carsharing type: 2 levels one-way vs. two-way) on income and also on cars per household. For income, we found that there was a main effect of affordability $[\mathrm{F}(2)=239.77$, $\mathrm{p}<.001]$, a main effect of carsharing type $[\mathrm{F}(1)=8.11, \mathrm{p}<.01]$, but no interaction $[\mathrm{F}(2,1)=0.39, \mathrm{p}=.68]$. This suggests that participants who reported higher affordability had higher incomes, one-way carsharing members had higher incomes than two-way members, but the difference between one-way and two-way members remained the same across affordability levels. For the number of cars owned per household, we found that there was a main effect of affordability $[F(2)=7.94$, p $<.001]$, a main effect of carsharing type $[\mathrm{F}(1)=81.29, \mathrm{p}<.001]$, but no interaction $[\mathrm{F}(2,1)=1.04, \mathrm{p}=.35]$. This suggests that participants who reported higher affordability owned more cars than participants with low affordability, one-way carsharing members owned more cars than two-way members, but the difference between one-way and two-way members remained the same across affordability levels.

One possible explanation for the discrepancies in affordability and income between carshare populations is that two-way members own fewer cars than one-way members. On average, one-way members own 1 car per household, whereas two-way members own less than 0.4 cars per household. The total annual cost to own and maintain a car in British Columbia is estimated to be $\$ 9000$ (Canadian Auto Association). Such a financial obligation can be a significant strain on finances and impact reported affordability of lifestyle. Owning multiple cars can compound this. As an example, the respondents in the second highest income bracket $(\$ 100,000-\$ 149,999)$ who claimed to find their lives "unaffordable or close to unaffordable" $(n=73)$ averaged 1.13 cars per household, compared to 0.84 cars per household for respondents who could "comfortably meet our present and future needs" ( $n=230$ ) in the same income bracket.

Finally, we make one more observation on the income differences between the three affordability levels. In Table 3, the income difference between affordability level of 0 and 1 is around $\$ 11,000$, but the income difference between affordability level of 1 and 2 is around $\$ 40,000$. Moreover, one-way members in the lowest affordability group (who view life as "unaffordable or close to unaffordable") make \$3000 more per year than two-way members in the same affordability group. Members in the middle and upper affordability groups make $\sim \$ 11,000$ more per year than two-way members.

\section{Summary and discussion}

In this paper we aimed to understand motivations for carsharing. Our findings highlight key differences between one-way and two-way carsharing members in their motivations for carsharing, private vehicle ownerships, and modes and frequency of travel. We found that two-way carsharing members view carsharing as a way to live efficiently, save money, be environmentally friendly, and reduce their dependence on car ownership. Two-way members also make more use of walking and biking. In contrast, one-way members are more concerned with added convenience and are likely to see carsharing as a viable replacement for taxi or ride-hailing. They also take more than three times as many trips by private vehicle and twice as many trips by carshare vehicle as two-way members. These trip mode and frequency patterns are consistent across demographic variable levels.

The high membership cost of two-way carsharing has limited access to this option for the lowest income category in our respondent sample. However, where households have chosen to adopt two-way carsharing instead of car ownership, self-reported affordability of lifestyles is higher than those who have joined one-way carsharing. This group is also characterized by car ownership rates that are 2.5 times higher than two-way carsharing members, with $70 \%$ of one-way members owning at least one private vehicle compared to only $30 \%$ of two-way members. One-way respondents who own at least one vehicle average 5.1 trips per week, while two-way members who own at least one vehicle average only 3.8 trips per week.

We initially thought there may be one of two primary motivations for carsharing: either a lifestyle choice or a financial imperative. What we found instead is that motivations varied by carsharing membership type. While promoters of one-way carsharing correctly identify it as a lifestyle choice of millennials, these younger, wealthier individuals tend to own more cars and feel greater pressure from their lifestyle on their financial wellbeing, compared to two-way carsharing members who are less wealthy but report greater ease of lifestyle affordability.

We note that the differences in carsharing motivations and travel patterns between one-way and two-way members were correational, not causal. Although out results did not show a causal direction, there was nonetheless an association between carsharing type and motivations and travel patterns. This association has two interpretations. One is that people's motivations and lifestyle preferences determine their carsharing choice. That is, people who are wealthier, own more private vehicles, and want convenience are more likely to choose one-way carsharing. People who care about financial savings and a more efficient sustainable lifestyle are more likely to choose two-way carsharing. The other interpretation is that the choice of carsharing reinforces motivations and lifestyle preferences. That is, one-way carsharing reinforces the idea of convenience, and two-way carsharing reinforces the idea of savings and a more efficient, sustainable lifestyle.

This study shows strongly differentiated motivatons by type of carsharing membership. We do not claim causality but association, We believe, there are many different motivations for how the public use different modes of transport. Neglecting such differences can lead to perceptions of constradictory results such as those found in analysis of the impact of ridehailing on other modes of transit (Hall et al., 2018, Sadowsky and Helson, 2017, Clewlow and Mishra, 2017). We believe what appear to be contraditions is likely to be heterogeneity of motivations and preferenecs within the pool of ridehailing users - as found here among carsharing users. Future studies on the effects of shared transportation may want to examine discongruities within the user base, taking differing motivations and lifestyles into account. By better understanding these underlying populations, the findings can be better contextualized.

Our analysis identified at least two distinct populations of carshare users. Within these distinct populations, we suspect that the choice of carsharing reinforces lifestyle preferences. However, we acknowledge that this study cannot sufficiently address this question. We believe long-term studies or randomized control trials are needed to assess whether a lifestyle built around the 
flexibility of one-way carsharing is harbinger of a greater tendency to rely on private car ownership in the future. The corollary would suggest two-way members grow accustomed to using public transit, active modes of travel and become more efficient at trip planning when needing a prviate vehicle. These traits help reduce future car ownership.

Municipal governments' ultimate goal is sustainable urban transportation. This requires far more than reducing congestion and GHG emissions. The advent of each new mode of transport, from ridehailing to shared scooters, adds to the portfolio of travel modes and their impact on society and the environment. Understanding user motivations for each mode of transport will help municipal governments fashion policies that serve their citizens in a sustainable manner.

\section{Acknowledgements}

We are grateful to four anonymous referees for very helpful comments and suggestions. We are also grateful to Jonn Axsen and Benjamin Sovacool for their guidance in how we should improve this original work.

We are grateful for the support of the Vancity Credit Union in creating, managing, and distributing the survey. We would also like to acknowledge the support from the four Vancouver carsharing organizations: Modo, Evo, Car2go, and Zipcar, who helped by distributing the survey to their member bases.

Finally, we acknowledge financial support from the Center for Climate and Energy Decision Making (CEDM) - a cooperative agreement between the National Science Foundation (SES-1463492) and Carnegie Mellon University. We are also grateful for the generous support of the Canada Research Chair.

\section{Appendix A. Supplementary material}

Supplementary data to this article can be found online at https://doi.org/10.1016/j.trd.2018.12.010.

\section{References}

Clark, B., Lyons, G., Chatterjee, K., 2016. Understanding the process that gives rise to household car ownership level changes. J. Transp. Geogr. 55, 110-120.

Clewlow, R., Mishra, G., 2017. The Adoption, Utilization, and Impacts of Ride-Hailing in the United States. UC Davis Institute of Transportation Studies Research Report. UCD-ITS-RR-17-07.

City of Vancouver, 2017. Street and Traffic By-Law NO. 2849.

Dargay, J.M., 2000. The effect of income on car ownership: evidence of asymmetry. Transp. Res. Part A 35, 807-821.

de Winter, J., Dodou, D., 2010. Five-point likert items: t test versus Mann-Whitney-Wilcoxon. Pract. Assess., Res. Eval. No. 15, 11.

Hall, J., Palsson, C., Price, J., 2018. Is Uber a substitute or complement for public transit? J. Urban Econ. 108, 36-50.

Kashani, H.B., Trépanier, M., 2018. A Typology of Carsharing Customers in Montreal Based on Large-Scale Behavioural Dataset. CIRRELT-2018-16.

Martin, E., Shaheen, S.A., Lidicker, J., 2010. Impact of carsharing on household vehicle holdings: results from North American shared-use vehicle survey. Transport. Res. Rec.: J. Transport. Res. Board 2143, 150-158.

Martin, E., Shaheen, S.A., 2011. Greenhouse gas emission impacts of carsharing in North America. IEEE Trans. Transport. Syst. $12,1074-1086$.

McElhanney, 2017. City of Vancouver Transportation Panel Survey 2016 Final Report, pp. 1-97.

Metro Vancouver, 2016. Number of Registered Vehicles 2001-2016. Retrieved from < www.metrovancouver.org > .

Millard-Ball, M., Murray, G., Ter Schure, J., Fox, C., Burkhardt, J., 2005. Car-Sharing: Where and How It Succeeds. Transit Cooperative Research Program (TCRP) Report 108. Published by Transportation Research Board, Washington.

Namazu, M., 2017. The evolution of carsharing: heterogeneity in adoption and impacts (T). University of British Columbia. Retrieved from < https://open.library. ubc.ca/cIRcle/collections/24/items/1.0343460 > .

Namazu, M., Dowlatabadi, H., 2015. Characterizing the GHG emission impacts of carsharing: a case of Vancouver. Environ. Res. Lett. 10 (12), 1-10. https://doi.org/ 10.1088/1748-9326/10/12/124017.

Namazu, M., Dowlatabadi, H., 2018. Vehicle ownership reduction: a comparison of one-way and two-way carsharing systems. Transp. Policy 64, 38-50.

New York City Department of Transportation, 2017. Carshare Permit Application.

Nolan, A., 2010. A dynamic analysis of household car ownership. Transp. Res. Part A 44, 446-455.

Oakil, A.T.M., Manting, D., Nijland, H., 2016. Determinants of car ownership among young households in the Netherlands: the role of ubranisation and demographic and economic characteristics. J. Transp. Geogr. 51, 229-235.

Sadowsky, N., Nelson, E., 2017. The Impact of Ride-Hailing Services on Public Transportation Use: A Discontinuity Regression Analysis. Economics Department Working Paper Series, 13.

Schaefers, T., 2013. Exploring carsharing usage motives: a hierarchical means-end chain analysis. Transport. Res. Part A: Policy Pract. 47, 69-77. https://doi.org/10. 1016/j.tra.2012.10.024.

Shaheen, S.A., 2017. Carsharing Trends and Research Highlights.

Shaheen, S.A., Sperling, D., Wagner, C., 1999. A Short History of Carsharing in the 90s. Institute of Transportation Studies.

Shen, Q., Chen, P., Haixiao, P., 2016. Factors affecting car ownership and mode choice in rail transit-supported suburbs of a large Chinese city. Transp. Res. Part A 94, 31-44.

Statistics Canada, 2011. Table 203-0021 - Survey of household spending (SHS), household spending, Canada, regions and provinces, annual (dollars), CANSIM (database). Retrieved from < http://cansim2.statcan.gc.ca/ > .

Wielinski, G., Trépanier, M., Morency, C., 2015. What about free-floating carsharing? Transport. Res. Rec.: J. Transport. Res. Board 2536, 28-36. https://doi.org/10. 3141/2536-04.

Vancity, 2018. Changing Gears: Exploring the Car-Sharing Culture Shift in Metro Vancouver, pp. 1-17. 